Pesq. Vet. Bras. 31(5):452-458, maio 2011

\title{
Lactacidemia e concentrações séricas de aspartato aminotransferase e creatinoquinase em equinos da raça Quarto de Milha usados em provas de laço em dupla ${ }^{1}$
}

INDEX TERMS: AST, CK, lactate, roping competition, exercise, horses.

RESUMO.- O presente estudo teve por objetivo avaliar a influência do exercício físico de alta intensidade e curta duração (provas de laço em dupla) sobre a lactacidemia e as concentrações séricas de aspartato aminotransferase (AST) e creatinoquinase (CK) em equinos durante competição realizada no estado do Espírito Santo. Para tal foram obtidas amostras de soro e plasma de 20 equinos, da raça

\footnotetext{
${ }^{1}$ Recebido em 7 de outubro de 2010.

Aceito para publicação em 4 de fevereiro de 2011.

2 Programa de Mestrado em Ciência Animal, Centro Universitário Vila Velha (UVV), Rua Comissário José Dantas de Melo 21, Vila Velha, ES 29102-770, Brasil. *Autor para correspondência: clarisse.coelho@uvv.br

${ }^{3}$ Laboratório Clínico Veterinário, UVV, Rua Comissário José Dantas de Melo 21, Vila Velha, ES.
}

Quarto de Milha ou mestiços, em três momentos assim definidos: no repouso, uma semana antes da prova atlética, já com o animal em treinamento (T0); antes da prova atlética (T1) e imediatamente após o término da mesma (T2). As referidas amostras foram encaminhadas ao Laboratório Clínico do Centro Universitário Vila Velha (UVV) para as análises. Na avaliação da lactacidemia, os resultados registrados nos momentos T0, T1 e T2 foram, respectivamente, de $0,49 \pm 0,24 \mathrm{mmol} / \mathrm{L}, 0,93 \pm 0,16 \mathrm{mmol} / \mathrm{L}$ e $9,86 \pm 2,09 \mathrm{mmol} / \mathrm{L}$. Na avaliação da atividade sérica de AST, os resultados registrados nos momentos T0, T1e T2 foram, respectivamente, de $189,1 \pm 43,6 \mathrm{UI} / \mathrm{L}, 210,2 \pm 46,7 \mathrm{UI} / \mathrm{L}$ e $173,1 \pm 33,5$ UI/L. Por fim, a avaliação da atividade sérica da CK nos momentos T0,T1 e T2 foram, respectivamente, de 110,9 $\pm 35,2$ UI/L, 51,8 $\pm 15,4$ UI/L e 88,2 $\pm 33,5$ UI/L. A análi- 
se dos resultados demonstrou que o exercício físico imposto levou ao aumento significativo de lactato plasmático e CK sérica e não alterou o AST sérico e que a interpretação destes resultados permitiu concluir que os equinos usados estavam aptos ao nível de exercício físico imposto.

TERMOS DE INDEXAÇÃO: AST, CK, lactato, laço em dupla, exercício, equinos.

\section{INTRODUÇÃO}

O exercício físico desencadeia diferentes respostas biológicas (Kienzle et al. 2006). A compreensão de tais mecanismos fisiológicos e o estabelecimento de parâmetros que podem ser avaliados durante o treinamento são de enorme importância na avaliação da performance destes animais (Marques 2002, Tateo et al. 2008), mas para tal eles devem ser bem caracterizados.

A produção e utilização adequadas de energia são essenciais para o ótimo desempenho do equino atleta (Gomide et al. 2006). Eaton et al. (1995) citam que a energia gasta para a realização de atividades físicas de alta intensidade em equinos é 50 vezes superior à necessária no repouso. Esta energia é proveniente de moléculas de ATP, cuja produção poderá ocorrer através da degradação do glicogênio muscular (Lacombe et al. 2003) e com a degradação das moléculas de glicose por via aeróbica e/ou por via anaeróbica, com subseqüente produção de lactato. Independente do tipo do exercício, alta ou baixa intensidade, curta ou longa duração, todas as vias de produção de energia são ativadas e o que determina qual será predominante é a intensidade e duração do mesmo.

Os valores basais de lactato plasmático oscilam no repouso entre 0,5-1,0mmol/L, segundo McGowan (2008) em cavalos de corrida. Após corrida ou esforço submáximo, as concentrações séricas podem atingir até $25-30 \mathrm{mmol} / \mathrm{L}$ (McGowan 2008). Se as concentrações atingirem $30 \mathrm{mmol} / \mathrm{L}$ após a corrida, há declínio do $\mathrm{pH}$ sanguíneo para 7,0 e a acidemia resultante leva a fadiga muscular, disfunção de mitocôndria, prejuízo a glicólise e redução de ATP muscular com miopatia (Pösö 2002). De uma forma geral, o aumento da concentração de lactato plasmático poderá ser usado para indicar a capacidade atlética do cavalo visto que animais que apresentam grande capacidade aeróbica geralmente têm baixas elevações das concentrações de lactato em resposta ao exercício ou apresentam uma clearance mais eficiente (Hodgson \& Rose 1994, Valberg 2008). Corroborando com esta informação, Falaschini \& Trombetta (2001) citam que após o exercício o aumento da concentração de lactato é uma consequência do treinamento, sendo maior nos equinos submetidos a provas de alta intensidade, e o tempo de retorno aos valores basais seria também um índice da capacidade de recuperação do animal. Art \& Lekeux (2005) também confirmam que o treinamento aumenta a taxa de remoção do lactato produzido pelo músculo, melhorando a capacidade tamponante citoplasmática.

A enzima aspartato aminotransferase (AST) é uma enzima citoplasmática e mitocondrial presente em diversos te- cidos, com maior destaque para fígado e músculos esquelético e cardíaco, sendo, portanto, bastante usada no diagnóstico de afecções acometendo estes órgãos (Valberg 2008). Para equinos da raça PSI, em repouso, os valores médios para a atividade de AST obtidos por Valberg (2008) foram de 296,0 $\pm 70,0 \mathrm{UI} / \mathrm{L}$, enquanto que Robinson (2003) cita valores de 141-330 UI/L. Franciscato et al. (2006) descreveram valores médios de 209,67 UI/L para equinos da raça Crioula em treinamento. Pritchard et al. (2009) citaram valores de referência para AST entre 189 e 456 UI/L.

A creatinoquinase (CK) é uma enzima de alta especificidade para lesões musculares, sendo encontrada principalmente no citossol das células musculares (músculos esquelético e cardíaco), mas também nos rins, cérebro, diafragma, trato gastrintestinal, útero e bexiga urinária (Valberg 2008). Valberg (2008) referiu valores de 12,9 $\pm 5,2$ $\mathrm{UI} / \mathrm{L}$ para a atividade enzimática de $\mathrm{CK}$ em equinos adultos. Robinson (2003) descreveu intervalo de referência de 2-147 UI/L para equinos da raça Puro Sangue Inglês e 18$217 \mathrm{UI} / \mathrm{L}$ para equinos de trote, Franciscato et al. (2006) citaram valores de 159,81 UI/L para cavalos da raça Crioula em treinamento e Pritchard et al. (2009) descreveram valores de 123-358 UI/L.

Balarin et al. (2005) destacam que são necessárias as determinações de valores de referência de AST e CK para equinos, das diferentes raças e submetidos aos diferentes tipos de exercício, visando a correta interpretação dos resultados obtidos principalmente porque estas duas enzimas podem sofrer a influência de fatores ambientais e de manejo, fato confirmado por Câmara e Silva et al. (2007). Brandi et al. (2008) ressaltam ainda que em seu experimento houve dificuldade em estabelecer padrão "normal" para cada animal, sendo necessário observar os valores plasmáticos basais das enzimas e depois o seu comportamento após a realização da atividade atlética. Pritchard et al. (2009) reforçam a importância do estabelecimento de valores de referência para equinos em atividade em condições climáticas tropicais (temperaturas elevadas e umidade elevada).

Geralmente, a determinação sérica da atividade da AST tem sido utilizada associada à CK e lactato desidrogenase (LDH) para a avaliação dos efeitos do exercício físico sobre a musculatura (Câmara e Silva et al. 2007, Valberg 2008). É sabido que a permeabilidade do sarcolema e mitocôndrias aumenta durante o exercício e LDH, CK e AST podem escoar para o plasma (Valberg 1996). Assim, as concentrações de AST e CK poderiam ser influenciadas pela fase de treinamento e pelo tipo de exercício (Câmara e Silva et al. 2007). Se a duração do exercício for mantido constante, a intensidade do mesmo determina o aumento de suas concentrações séricas (Harris et al. 1998).

Os resultados descritos na literatura são conflitantes, com alguns autores citando influência positiva ou a não interferência do exercício sobre estas variáveis sanguíneas (Rose et al. 1980, Freestone et al. 1991, Balarin et al. 2005, Kowal et al. 2006, Padalino et al. 2007).

Dentro da fisiologia do exercício eqüina, existem diver- 
sos estudos na literatura, principalmente envolvendo os parâmetros que permitem a avaliação da performance de cavalos de corrida e de enduro. Entretanto, poucos são os relatos envolvendo equinos usados em provas western, como as provas de laço em dupla, treinados em condições climáticas tropicais, como as encontradas no Brasil, fato também ressaltado por Martins et al. (2005). O objetivo do presente trabalho foi avaliar a influência do exercício físico, caracterizado por provas de laço em dupla, sobre a lactacidemia e sobre a atividade sérica das enzimas aspartato aminotransferase (AST) e creatinoquinase (CK) em equinos da raça Quarto de Milha e de mestiços durante competição realizada no estado do Espírito Santo.

\section{MATERIAL E MÉTODOS}

Foram utilizados 20 equinos da raça Quarto de Milha, ou mestiços da referida raça, sendo 18 machos e duas fêmeas, pesando em média $500 \mathrm{~kg}$, com idade variando entre cinco e 14 anos (média de nove anos de idade), considerados clinicamente hígidos, mediante exames clínicos e laboratoriais incluindo hemograma. Estes animais pertencem a criatórios localizados na região da grande Vitória, estado do Espírito Santo.

Os eqüinos pesquisados são submetidos ao mesmo tipo de manejo alimentar e sanitário, sendo utilizados em provas de laço em dupla, cuja descrição está descrita em delineamento experimental. Todos os eqüinos selecionados encontravam-se no mesmo estágio de treinamento (três a quatro vezes na semana são aquecidos e treinados no ritmo da prova e nos demais dias são submetidos a galopes - treinos com duração media de duas horas) e executavam tal atividade há pelo menos dois anos. O treinamento só foi interrompido 24 horas antes da prova para o transporte dos animais até o local da competição.

As amostras de sangue foram obtidas em três momentos de cada um dos animais, sendo assim caracterizadas: momento repouso - T0 (obtida uma semana antes da prova atlética, com o animal em repouso, mas dentro do período de treinamento, no horário entre 8h:00 e 10h:00 da manhã), momento pré-prova - T1 (obtida antes da prova atlética) e momento pós-prova - T2 (obtida num período de até no máximo cinco minutos após a realização da atividade física). Para todos os animais usados, a amostra de sangue pós-prova foi coletada após a realização da primeira bateria completa de atividade, de forma a padronizar as coletas e avaliações. No dia da prova de laço foram registradas as condições de tempo (temperatura e umidade), bem como características da pista.

A prova de laço em dupla, também conhecida por team ropping, é uma prova onde uma dupla de cavaleiros laçam um bezerro, sendo um dos cavaleiros responsável em laçar a cabeça e o outro responsável em laçar os pés. O tempo da prova, em média de oito a 10 segundos, decorre desde o momento em que os laçadores saem do boxe até os dois cavaleiros laçarem o bezerro mantendo-o sobre a corda esticada e amarrada à sela do cavalo. Tal atividade física caracteriza um exercício de alta intensidade e curta duração.

As amostras de sangue foram obtidas, após antissepsia local, por meio de venopunção da jugular com agulhas descartáveis $(25,0 \times 0,8 \mathrm{~mm})$, utilizando-se sistema a vácuo ${ }^{4}$, em

\footnotetext{
4 Vacutainer.
}

tubos de vidro contendo anticoagulante EDTA-fluoreto de sódio com capacidade de $2 \mathrm{~mL}$, para avaliação plasmática de lactato; e em tubos de vidro siliconizados sem anticoagulante com capacidade de $9 \mathrm{~mL}$, para as determinações séricas de AST e CK. Todas as amostras foram transportadas sob refrigeração ao Laboratório Clínico Veterinário do Centro Universitário Vila Velha (UVV) para processamento. As amostras obtidas em frascos sem anticoagulante e com anticoagulante EDTAfluoreto de sódio foram imediatamente centrifugadas durante 10 minutos (Centrífuga modelo TDL80-2B, Marca Centribio) a 4000 rpm para separação de, respectivamente, soro e plasma.

A determinação de lactato plasmático foi realizada através de metodologia enzimática, utilizando kit comercial (KATAL LOD-PAP), segundo metodologia de Pryce (1969), em analisador bioquímico semi-automático (Bioplus - BIO 200).

No soro, a atividade da aspartato aminotransferase (AST) foi determinada através de kit comercial (Bioclin - K048), em analisador bioquímico semi-automático (Bioplus - BIO 200), em comprimento de onda de $340 \mathrm{~nm}$ (Bergmeyer 1974). Também no soro, a atividade da creatinoquinase (CK) sérica foi quantificada em analisador bioquímico semi-automático (Bioplus - BIO200), em comprimento de onda de $340 \mathrm{~nm}$, utilizando-se kit comercial (Bioclin - K010) (Schimid \& Forstner 1986).

A análise dos resultados - AST e CK séricos, e lactato plasmático - foi realizada utilizando-se o programa estatístico computadorizado GraphPad InStat (versão 3.0). Devido à distribuição gaussiana dos dados, os mesmos foram avaliados através de testes paramétricos (análise de variância - ANOVA e teste de Tukey) para comparação entre médias com nível de significância de 5\%. Nestas análises levou-se em consideração a influência do exercício físico nos níveis das variáveis estudadas, todos em amostras sanguíneas de cavalos usados em prova de laço em dupla.

\section{RESULTADOS}

Nos exames clínicos e laboratoriais realizados para seleção dos equinos usados na presente pesquisa os valores médios registrados foram: frequência cardíaca de $30 \mathrm{bpm}$, frequência respiratória de $14 \mathrm{mpm}$, motilidade intestinal presente à auscultação, mucosas róseas e temperatura retal de $38,2^{\circ} \mathrm{C}$. Os valores de hemograma encontravam-se dentro da normalidade para a espécie conforme Robinson (2003).

Os registros das condições meteorológicas no dia da prova, obtidos junto à jornais do dia revelaram temperatura ambiente média de $29^{\circ} \mathrm{C}$ e umidade relativa do ar de $80 \%$, características de clima tropical. A pista de areia encontrava-se seca.

No Quadro 1, estão apresentados os valores médios e desvios-padrão para os valores plasmáticos de lactato e valores séricos de AST e CK, bem como os valores de $p$ obtidos na análise de variância (ANOVA).

É possível observar que houve aumento significativo no lactato plasmático imediatamente após a realização da prova, em cujo momento os valores oscilaram entre 5,66 e $13,12 \mathrm{mmol} / \mathrm{L}$ quando comparados os valores registrados nos momentos repouso e antes da prova.

$\mathrm{Na}$ avaliação dos valores séricos de AST é possível observar que houve redução estatisticamente significativa entre os momentos antes e logo após a atividade física, 
Quadro 1. Valores médios e desvios-padrão da concentração de lactato plasmático e de AST e CK séricos nos equinos da raça Quarto de Milha usados em prova de laço em dupla nos momentos repouso (uma semana antes da atividade atlética, em treinamento), imediatamente antes e imediatamente após a realização da prova atlética

\begin{tabular}{lcccc}
\hline & T0 & T1 & T2 & p \\
\hline $\begin{array}{l}\text { Lactatoplas- } \\
\text { mático(mmol/l) }\end{array}$ & $0,49 \pm 0,24^{\mathrm{a}}$ & $0,93 \pm 0,16^{\mathrm{a}}$ & $9,86 \pm 2,09^{\mathrm{b}}$ & $<0,0001$ \\
AST $(\mathrm{UI} / \mathrm{l})$ & $189,1 \pm 43,6^{\mathrm{a}, \mathrm{b}^{*}}$ & $210,2 \pm 46,7^{\mathrm{a}}$ & $173,1 \pm 33,5^{\mathrm{b}}$ & 0,0238 \\
CK $(\mathrm{UI} / \mathrm{l})$ & $110,9 \pm 35,2^{\mathrm{a}}$ & $51,8 \pm 15,4^{\mathrm{b}}$ & $88,2 \pm 33,5^{\mathrm{c}}$ & $<0,0001$
\end{tabular}

* Letras minúsculas diferentes na mesma linha denotam diferença estatística significativa entre as medias $(p<0,05)$ obtido pelo teste ANOVA. T0 (obtida uma semana antes da prova atlética, com o animal em repouso, mas dentro do período de treinamento, no horário entre 8h:00 e 10h:00 da manhã), momento pré-prova - T1 (obtida antes da prova atlética) e momento pós-prova - T2 (obtida num período de até no máximo cinco minutos após a realização da atividade física.

destacando que o maior valor nos três momentos foi registrado no momento antes da realização da prova atlética. $\mathrm{Na}$ avaliação da atividade sérica de $\mathrm{CK}$, o maior valor foi registrado no momento repouso, seguido de uma redução significativa no momento antes do exercício, quando foi registrado o menor valor. Após o exercício físico foi registrado aumento significativo.

\section{DISCUSSÃO}

Há longo tempo é sabido que os diversos tipos de exercício ou atividade física geram alterações no organismo animal. As principais alterações exteriores observadas estão relacionadas com a hipertrofia de musculatura de trabalho observada com o treinamento constante, principalmente nos equinos que realizam as chamadas provas de explosão, ou seja, exercícios de alta intensidade e curta duração. Isto levava consequentemente a um bom desempenho dos equinos nas diversas competições. Porém, o improviso e a falta de métodos científicos de condicionamento e de preparação com atividades físicas desastrosas ("overtraining") podem levar, até hoje, a retirada de equinos promissores de várias modalidades atléticas (Thomassian et al. 2005, Tateo et al. 2008).

Apesar de, nas últimas décadas, muitas pesquisas terem sido direcionadas ao estudo dos efeitos dos exercícios, de diferentes intensidades e duração, sobre as diversas variáveis sanguíneas, são consideradas ainda escassas as pesquisas realizadas no Brasil frente ao número de eqüinos em atividade atlética (Martins et al. 2005). O estabelecimento de valores de referência nacionais, seja no repouso ou após atividades atléticas, para as diferentes raças usadas nos esportes hípicos, é essencial para a correta interpretação dos resultados obtidos, visando a avaliação do condicionamento e melhora da performance atlética.

A avaliação das concentrações médias de lactato plasmático obtidas no momento de repouso, ou seja, uma semana antes da realização da prova, porém com o equino em treinamento, revelou valores semelhantes aos descri- tos por McGowan (2008) para cavalos de corrida. Também foram semelhantes às descrições nacionais de Marques et al. (2002) que trabalharam com equinos Puro Sangue Inglês submetidos a dois tipos de testes à campo.

O aumento dos valores plasmáticos de lactato é esperado após qualquer tipo de exercício, pois todas as fontes de energia são ativadas (McGowan 2008). Porém, este aumento é dependente principalmente da intensidade e da duração do mesmo (Santos 2006). A determinação plasmática de lactato após o exercício, portanto, permite determinar o nível de esforço físico ao qual os animais foram submetidos, bem como determinar o preparo dos referidos animais para realizar o exercício imposto, ao associar tais resultados com a avaliação clínica dos animais (Gomide et al. 2006). A análise dos valores registrados pós-prova na presente pesquisa permitiu a constatação de que houve predominância da produção de energia por via anaeróbica láctica, concordando com as descrições de Gomide et al. (2006), Kowal et al. (2006) e Tateo et al. (2008), visto que os valores foram superiores a $4 \mathrm{mmol} / \mathrm{L}$. Além disto, foi possível confirmar que a intensidade da atividade física imposta aos equinos da raça Quarto de Milha da presente pesquisa foi grande.

Corroborando com tal afirmativa, Santos (2006) destaca que exercício de alta intensidade promove aumento de lactato plasmático superior a $4 \mathrm{mmol} / \mathrm{L}$ e os exercícios de intensidade moderada caracterizariam aumentos plasmáticos entre 2,5 e 4mmol/L. Marques (2002) também comprovou tal afirmativa ao observar que nos equinos submetidos a exercício de baixa intensidade e curta duração não há aumento significativo nos valores de lactato, discordando de outros relatos. Tal fato foi justificado devido ao exercício imposto, por este pesquisador, ter sido considerado pouco exigente do ponto de vista atlético do equino e também que o nível de atividade imposto permitiu que o organismo fosse capaz de metabolizar o lactato produzido. O mesmo autor também relatou que naqueles animais submetidos a exercícios de alta intensidade e curta duração, semelhante ao executado pelos equinos Quarto de Milha nas provas de laço em dupla, houve aumento significativo do lactato plasmático, com valores atingindo $2,12 \mathrm{mmol} / \mathrm{L}$. Este valor foi inferior ao descrito no presente estudo, onde detectaram-se valores de $9,86 \pm 2,09 \mathrm{mmol} / \mathrm{L}$ no pós-exercício imediato. Por se tratarem de pesquisas que submeteram os equinos a um nível de esforço físico semelhante, esta disparidade de valores pode ser atribuída ao momento da coleta, visto que no trabalho de Marques (2002) as amostras de sangue foram obtidas $30 \mathrm{mi}-$ nutos após o término da atividade física e na presente pesquisa a amostras foram coletadas imediatamente após o término da mesma, conforme recomenda Keadle et al. (1993), que citam que o pico de lactato plasmático ocorre em até 10 minutos após o exercício.

A magnitude de elevação foi semelhante às descrições de Pinkowski et al. (1998), Ferraz (2006) e Gomide et al. (2006), que respectivamente trabalharam com trote, exercício progressivo em esteira e CCE. Isto pode sugerir uma 
intensidade da atividade física executada semelhante entre estes estudos, bem como, principalmente nos estudos que usaram equinos rotineiramente trabalhados em provas de resistência, uma baixa taxa de remoção do lactato produzido em decorrência da duração prolongada de atividade. Portanto, uma análise criteriosa deve ser feita sempre levando em consideração o nível de intensidade e duração impostos no exercício físico.

Ainda relacionando a produção de lactato plasmático com a intensidade do exercício, Davie \& Evans (2000) citaram que em provas com distância de até $800 \mathrm{~m}$, semeIhante ao percurso percorrido pelo equinos na prova de laço em dupla, os valores de lactato plasmático atingem 4 a $19 \mathrm{mmol} / \mathrm{L}$ após o exercício, sendo o aumento da concentração de lactato proporcional à intensidade da atividade física. Dentro deste intervalo encaixa-se o valor médio registrado no presente estudo.

Nenhum dos equinos utilizados atingiu valores pós-prova tão elevados quanto os descritos por Pösö (2002), que descreveu concentrações plasmáticas de lactato de até $30 \mathrm{mmol} / \mathrm{L}$ após exercício submáximo, podendo levar inclusive à miopatia. Todos os equinos aqui analisados seguiram em outras provas no mesmo dia, não demonstrando alterações clínicas.

A avaliação das atividades séricas de AST e CK frente ao exercício mostrou-se um desafio a parte dentro do presente trabalho. Existem grandes diferenças na literatura consultada referente aos valores considerados de repouso e valores obtidos após a realização de uma atividade atlética. Estas enzimas sofrem influência de diversos fatores tais como raça, idade, tipo e duração do exercício imposto, além de fatos ambientais e de manejo, segundo Balarin et al. (2005) e Câmara e Silva et al. (2007). Brandi et al. (2008) reforçam a grande dificuldade na comparação com a literatura visando estabelecer normalidade dos resultados encontrados e sugerem que a avaliação dos efeitos do exercício físico seja feita através da comparação com o valor basal, no repouso, obtido do próprio animal.

É importante ressaltar a necessidade de associar os resultados encontrados com o exame clínico criterioso do animal após a realização do exercício, visto que estas enzimas são rotineiramente usadas para diagnóstico de lesões musculares (Valberg 2008). Porém, em todos os momentos de avaliação, os valores foram bem inferiores aos descritos por Janssen et al. (1989), Harris et al. (1998) e Aleman (2008), além do fato que clinicamente os equinos não demonstraram quaisquer alterações e seguiram bem para as fases seguintes das provas.

A maioria dos relatos na literatura descreve atividades e protocolos realizados fora do Brasil. E dentre os nacionais (Balarin et al. 2005, Gomide et al. 2006, Brandi et al. 2008), grande maioria é executada em equinos de enduro e em condições controladas usando esteira ergométrica, o que dificultou ainda mais a análise dos resultados da presente pesquisa.

No presente estudo, os valores apresentados para a enzima AST pelos equinos antes do treinamento, ou seja nos momentos repouso e imediatamente antes da prova, foram semelhantes aos observados por Spinha de Toledo et al. (2001), Robinson (2003), Franciscato et al. (2006), Valberg (2008) e Pritchard et al. (2009) e inferiores aos relatados por Balarin et al. (2005).

Após a prova de laço em dupla foi possível observar uma redução significativa em relação ao valor obtido imediatamente antes da atividade física, discordando de várias citações da literatura conforme descrições a seguir. Segundo Snow, Ricketts \& Mason (1983), Valberg (1996) e Tateo et al. (2008), ocorre aumento da permeabilidade do sarcolema frente ao exercício físico e Câmara e Silva et al. (2007) complementam que o aumento de suas concentrações séricas seria influenciado pela fase do treinamento e o tipo de exercício físico. Corroborando com isto, Freestone et al. (1991) descreveram aumento em 35\% da atividade sérica de AST após o galope.

Entretanto, outros autores (Spinha de Toledo et al. 2001, Balarin et al. 2005, Martins et al. 2005, Kowal et al. 2006) descreveram que os valores séricos de AST não apresentaram em seus trabalhos diferenças significativas após trote, galope ou enduro, ou seja, em diferentes intensidades de exercício. Se for feita a comparação dos valores registrados logo após a prova de laço em dupla com o momento repouso, é possível notar que não há diferença significativa, da mesma forma ocorre na comparação dos valores repouso e antes da prova onde também não há diferença significante. Isto pode sugerir que não houve influência do exercício sobre a concentração sérica de AST. E que a tendência ao aumento no momento antes da prova em relação ao repouso seja ainda reflexo de atividade física realizada até 24 horas antes do transporte.

Segundo Siciliano et al. (1995) e Câmara e Silva et al. (2007), o treinamento pode atenuar o aumento da atividade sérica de AST após exercício físico. Porém, conforme já citado, não foi possível na presente pesquisa confirmar que o treinamento físico reduz a magnitude do aumento de AST sérico após o exercício porque nenhuma avaliação clínica e laboratorial dos mesmos animais foi feita previamente ao treinamento de forma a ser comparada com os resultados obtidos após a prova realizada. Além disto, Thomassian (2010) descreveram que o pico de AST após atividade física ocorre com 24 horas. Portanto, para se afirmar que não houve aumento da concentração sérica desta enzima, amostra de sangue deveria ser avaliada neste momento e isto não foi feito neste estudo.

No presente estudo, os valores apresentados para a enzima CK pelos equinos antes do treinamento, ou seja, nos momentos repouso e imediatamente antes da prova, foram semelhantes aos observados por Robinson (2003), superiores aos relatados por Valberg (2008) e inferiores às descrições de Franciscato et al. (2006) e Pritchard et al. (2009).

Após a execução da prova de laço em dupla foi possível observar um aumento significativo em relação ao valor de CK obtido imediatamente antes da atividade física, concordando com Valberg (1996), Spinha de Toledo et al. (2001), Balarin et al. (2005) e Kowal et al. (2006). A magni- 
tude de elevação e valores semelhantes aos descritos por Martins et al. (2005), que trabalharam com animais de enduro, e bem inferiores às descrições de Rose, Arnold \& Church (1980), avaliando equinos de corrida e de enduro. Novamente, a justificativa de todos estes autores para o aumento da concentração sérica de CK após o exercício foi o aumento da permeabilidade do sarcolema. Da mesma forma que AST, o aumento de CK também é influenciado pela fase de treinamento e tipo de exercício (Câmara e Silva et al. 2007). Franciscato et al. (2006) ainda ressaltam que um aumento não acentuado em CK após a atividade física pode ser esperado nos casos em que um programa de treinamento adequado ajustado ao condicionamento físico do animal tenha sido implantado, com tais achados sugerindo adaptação ao programa de exercícios. Porém a influência do treinamento sobre a atividade sérica desta enzima não foi constatado nesta pesquisa. Entretanto, é possível afirmar que o aumento observado no presente estudo não refletiu lesão muscular, visto que os valores registrados após o exercício encontram-se dentro da normalidade segundo Robinson (2003) e Pritchard et al. (2009) e clinicamente os animais encontravam-se bem. Padalino (2007), cujo trabalho envolveu a comparação de equinos em treinamento e equinos submetidos a esforço extremo, encontrou valores bem superiores de AST $(510,70$ $\mathrm{UI} / \mathrm{L}$ para AST e $284,50 \mathrm{UI} / \mathrm{L}$ para CK nos animais com fadiga). Novamente é importante ressaltar que as diferenças dos valores encontrados em todas as fases de avaliação podem ser decorrentes das diferenças nas raças estudadas e dos fatores ambientais e de manejo.

A diferença significativa observada na comparação dos valores de CK obtidos no momento repouso, quando foi registrado o maior valor, e no momento imediatamente antes da prova, não era esperada. Uma possível justificativa é que uma semana antes da prova os equinos estavam em pleno período de treinamento, o que poderia elevar os valores de CK da mesma forma como observamos esta elevação de suas concentrações após a execução da prova física (T1 para T2). Este treinamento foi suspenso pelo menos 24 horas antes do início da prova, momento de coleta do T1, para transporte dos animais de diversas regiões do estado até o local da prova. Portanto, os equinos ficaram pelo menos 24 horas sem atividade. Os efeitos da continuidade deste treinamento até momentos antes do transporte são reforçados pela avaliação de AST, que demonstra a tendência ao aumento dos valores no momento T1 quando comparados a T0. Conforme citam Franciscato et al. (2006) e Thomassian (2010), AST leva 24 horas para atingir o pico circulatório enquanto CK leva de 4-6 horas. Sendo assim, se continuaram a serem exercitados até momentos antes do transporte, isto pode ter gerado aumento da permeabilidade do sarcolema, conforme justificado acima, e a elevação de AST demorou mais a ser detectada, sendo registrada em T1, do que a elevação de CK, cujo momento de pico ocorreu no intervalo entre T0 e T1.

As diferenças observadas com relação aos valores obtidos por outros autores, tanto para AST quanto para CK, reforçam a importância do estabelecimento de valores regionais e dos grupo de eqüinos trabalhados e função executada para as referidas variáveis sanguíneas, de forma que a tornar tais exames laboratoriais ferramentas valiosas na avaliação da atividade física dos equinos.

\section{CONCLUSÕES}

Os resultados da presente pesquisa nos permitiram concluir que o exercício físico imposto gerou uma elevação significativa nos valores séricos de CK e nos valores plasmáticos de lactato, porém sem alteração nos valores séricos de AST.

A associação de tais achados, cujos valores encontravam-se dentro de limites fisiológicos normais no pós-exercício, com o exame clínico nos permitiu concluir também que os equinos usados na referida prova encontravam-se fisicamente condicionados ao exercício que realizaram, com o exercício imposto não sendo capaz de gerar fadiga nestes animais.

Agradecimentos.- À Fundação de Amparo à Pesquisa do Espírito Santo (FAPES), pela concessão da bolsa de mestrado.

\section{REFERÊNCIAS}

Aleman M. 2008. Neuromuscular disorders: A review of equine muscle disorders. Neuromuscular Disorders 18:277-287.

Art T. \& Lekeux P. 2005. Exercise-induced physiological adjustments to stressful conditions in sport horses. Livestock Prod. Sci. 92:101111.

Balarin M.R.S., Lopes R.S., Kohayagawa A., Laposy C.B. \& Fonteque J.R. 2005. Avaliação da glicemia e da atividade sérica de aspartato aminotransferase, creatinoquinase, gama-glutamiltransferase e lactato desidrogenase em equinos puro sangue inglês (PSI) submetidos a exercícios de diferentes intensidades. Semina, Ciênc. Agrárias 26(2):211-218.

Bergmeyer H.U. 1974. Methods of Enzymatic Analysis. Academic Press, New York. 1064p.

Brandi R.A., Furtado C.E., Martins E.N., Freitas E.V.V., Lacerda-Neto J.C. \& Queiroz-Neto A. 2008. Efeito de dietas com adição de oleo e do treinamento sobre a atividade muscular de equinos submetidos à prova de resistência. Acta Sci. Anim. Sci. 30(3):307-315.

Câmara e Silva I.A., Dias R.V.C. \& Soto-Blanco B. 2007. Atividades séricas de creatina quinase, lactato desidrogenase e aspartato aminotransferase em equinos de diferentes categorias de atividade. Arq. Bras. Med. Vet. Zootec. 59(1):250-252.

Davie A.J. \& Evans D.L. 2000. Blood Lactate responses to submaximal field exercise tests in thoroughbred horses. Vet. Journal 159:252258.

Eaton M.D., Evans D.L., Hodgson D.R. \& Rose R.J. 1995. Maximal accumulated oxygen deficit in Thoroughbred horses. J. Appl. Physiol. 78(4):1564-1568.

Falaschini A. \& Trombetta M.F. 2001. Modifications induced by training and diet in some exercise-related blood parameters in young trotters. J. Equine Vet. Sci. 21(12):601-604.

Ferraz G.C. 2006. Respostas endócrinas, metabólicas, cardíacas e hematológicas de equinos submetidos ao exercício intenso e à administração de cafeína, aminofilina e clembuterol. Tese de Doutorado, Faculdade de Ciências Agrárias e Veterinárias, Unesp, Jaboticabal. 98p. 
Franciscato C., Lopes S.T.A., Veiga A.P.M., Martins D.B., Emanuelli M.P. \& Oliveira L.S.S. 2006. Pesq. Agropec. Bras. 41(10):1561-1565.

Freestone J.F., Wolfsheimer K.J., Kamerling S.G., Church G., Hamra J. \& Bagwell C. 1991. Exercise induced hormonal and metabolic changes in Thoroughbred horses: Effects of conditioning and acepromazine. Equine Vet. J. 23(3):219-223.

Gomide L.M.W., Martins C.B., Orozco C.A.G., Sampaio R.C.L., Belli T., Baldissera V. \& Lacerda Neto J.C. 2006. Concentrações sanguíneas de lactato em equinos durante a prova de fundo do concurso completo de equitação. Ciência Rural 36(2):509-513.

Harris P.A., Marlin D.J. \& Gray J. 1998. Plasma aspartate aminotransferase and creatine kinase activities in thoroughbred racehorses in relation to age, sex, exercise and training. Veterinary Journal 155:295304.

Hodgson D.R. \& Rose R.J. 1994. Hematology and biochemistry, p.6378. In: Hodgson D.R. \& Rose R.J. (Eds), The Athletic Horse: Principle and practice of equine sports medicine. W.B. Saunders, Philadelphia.

Janssen G.M., Kuipers H., Willems G.M., Does R.J., Janssen E.P. \& Geurten P. 1989. Plasma activity of muscle enzymes: Quantification of skeletal muscle damage and relationship with metabolic variables. Int. J. Sports Med. 10(Suppl.3):60-108.

Keadle T.L., Pourciau S.S., Melrose P.A., Kammerling J.J. \& Horohov D.W. 1993. Acute exercise stresse modulates immune function in unfit horses. J. Equine Vet. Sci. 13(4):226-231.

Kienzle E., Freismuth A. \& Reusch A. 2006. Double blind placebo controlled vitamin E or selenium supplementation of Sport horses with unspecified muscle problems. J. Nutrition 136(7):2045-2047.

Kowal R.J., Almosny N.R.P., Cascardo B., Summa R.P. \& Cury L.J. 2006. Avaliação dos valores de lactato e da atividade sérica da enzima creatina quinase (2.7.3.2) em cavalos (Equus caballus) da raça Puro-Sangue-Inglês (PSI) submetidos a teste de esforço em esteira ergométrica. Revta Bras. Ciênc. Vet. 13(1):13-19.

Lacombe V.A., Hinchcliff K.W. \& Taylor L.E. 2003. Interactions of substrate availability, exercise performance and nutrition with muscle glycogen metabolism in horses. J. Am. Vet. Med. Assoc. 223(11): 1576-1585.

Marques M.S. 2002. Influência do exercício físico sobre os níveis de lactato plasmático e cortisol sérico em cavalos de corrida. Dissertação em Mestrado, Faculdade de Medicina Veterinária e Zootecnia, USP, São Paulo. 70p.

Marques M.S., Fernandes W.R., Coelho C.S. \& Mirandola R. 2002. Influência do exercício físico sobre os níveis de lactato plasmático e de cortisol sérico em cavalos de corrida. Hora Vet. 22(129):29-32.

Martins C.B., Orozco C.A.G., D'Angelis F.H.F., Freitas E.V.V., Christovão F.G., Queiroz Neto A. \& Lacerda Neto J.C. 2005. Determinação de variáveis bioquímicas em equinos antes e após a participação em provas de enduro. Revta Bras. Ciênc. Vet. 12(1/3):62-65.

McGowan C. 2008. Clinical pathology in the racing horse: The role of clinical pathology in assessing fitness and performance in the racehorse. Vet. Clin. North Am., Equine Pract. 24:405-421.

Padalino B., Rubino G., Centoducati P. \& Petazzi F. 2007. Training versus overtraining: Evaluation of two protocols. J. Equine Vet. Sci. 27(1):28-31.
Pinkowski W., Mohr E. \& Krzywanek H. 1998. Selected blood parameters during recovery from strenuous running exertion in trotters. J. Vet. Med. A 45(5):279-286.

Pösö A.R. 2002. Monocarboxylate transporters and lactate metabolism in equine athletes: A review. Acta Vet. Scand. 43(2):63-74.

Pritchard J.C., Burn C.C., Barr A.R.S. \& Whay H.R. 2009. Haematological and serum biochemical reference values for apparently healthy working horses in Pakistan. Res. Vet. Sci. 87:389-395.

Pryce J.D. 1969. A modification of Barker-Summerson method for the determination of lactic acid. Analyst. 94:1151-1152.

Robinson E.N. 2003. Current Therapy in Equine Medicine. $5^{\text {th }}$ ed. W.B. Saunders, Philadelphia. 960p.

Rose J.R., Arnold K.S. \& Church S. 1980. Plasma and sweat electrolyte concentrations in the horse during long distance exercise. Equine Vet. J. 12(1):19-22.

Santos V.P. 2006. Variações hemato-bioquímicas em equinos de salto submetidos a diferentes tipos de protocolos de exercício. Dissertação em Mestrado, Faculdade de Medicina Veterinária e Zootecnia, Universidade Federal do Rio Grande do Sul, Porto Alegre. 94p.

Schmid M. \& Fostner L.A. 1986. Laboratorie Testing in Veterinary Medicine Diagnosis in the Clinical Monitoring. Boehringer, Mannheim. 253p.

Siciliano P.D., Lawrence L.M., Danielsen K., Powell D.M. \& Thompson K.N. 1995. Effect of conditioning and exercise type on serum creatinekinase and aspartate aminotransferase activity. Equine Vet. J. 18(Suppl.):243-247.

Snow D.H., Ricketts S.W. \& Mason D.K. 1983. Haematological response to racing and training exercise in Thoroughbred horses, with particular reference to the leucocyte response. Equine Vet. J. 15(2):149-154.

Spinha de Toledo P., Domingues Junior M., Fernandes W.R. \& Magone M. 2001. Atividade sérica de aspartato aminotransferase, creatinoquinase, gama-glutamil transferase, lactato desidrogenase e glicemia em cavalos da raça PSI submetidos a exercícios de diferentes intensidades. Revta Bras. Ciênc. Vet. 8(2):73-77.

Tateo A., Valle E., Padalino B., Centoducati P. \& Bergero D. 2008. Change in some physiologic variables induced by Italian Traditional Conditioning in Standardbred Yearling. J. Eq. Vet. Sci. 28(12):743750.

Thomassian A., Watanabe M.J., Alves A.L.G., Hussni C.A., Nicoletti J.L.M. \& Fonseca B.P. 2005. Concentrações de lactato sanguíneo e determinação do V4 de cavalos da raça Árabe durante teste de exercício progressivo em esteira de alta velocidade. Archs Vet. Sci. 10(1):63-68.

Thomassian A. Medicina esportiva equina: da inspeção ao computador. Parte II. Disponível em <http//www.spmv.org.br/conpavet2004/ .../Armen\%20Tomassian-II.doc> (Acesso em 23 set. 2010).

Valberg S.J. 1996. Muscular causes of exercise intolerance in horses. Vet. Clin. North Am., Equine Pract. 12:495-515.

Valberg S.J. 2008. Skeletal muscle function, p.459-484. In: Kaneko J.J., Harvey J.W. \& Bruss M.L. (Eds), Clinical Biochemistry of Domestic Animals. $6^{\text {th }}$ ed. Academic Press, London. 